\title{
Water-in-Oil Microemulsions for Protein Delivery: Loading Optimization and Stability
}

\author{
Diego R. Perinelli ${ }^{1}$, Marco Cespi ${ }^{1}$, Stefania Pucciarelli ${ }^{2}$, Silvia Vincenzetti ${ }^{2, *}$, Luca Casettari ${ }^{3}$, \\ Jenny K.W. Lam ${ }^{4}$, Serena Logrippo ${ }^{1}$, Elisa Canala ${ }^{1}$, Mahmoud E Soliman ${ }^{5}$, Giulia Bonacucina ${ }^{1, *}$ \\ and Giovanni F. Palmieri ${ }^{1}$
}

${ }^{1}$ School of Pharmacy, University of Camerino, via Gentile III da Varano, 62032 Camerino, MC, Italy; ${ }^{2}$ School of Biosciences and Veterinary Medicine, University of Camerino, via Gentile III da Varano, 62032 Camerino, MC, Italy; ${ }^{3}$ Department of Biomolecular Sciences, School of Pharmacy, University of Urbino, Piazza del Rinascimento, 6, 61029 Urbino (PU), Italy; ${ }^{4}$ Department of Pharmacology \& Pharmacy, Li Ka Shing Faculty of Medicine, The University of Hong Kong, Pokfulam, Hong Kong, ${ }^{5}$ Department of Pharmaceutics and Industrial Pharmacy, Faculty of Pharmacy, Ain Shams University, Cairo, Egypt

\begin{tabular}{l} 
A R T I C L E H I S T O R Y \\
\hline Received: March 07, 2017 \\
Revised: May 02, 2017 \\
Accepted: May 02, 2017 \\
DOI: \\
10.2174/1389201018666170508112947
\end{tabular}

\begin{abstract}
Background: Microemulsions are attractive delivery systems for therapeutic proteins and peptides due to their ability to enhance bioavailability. Although different proteins and peptides have been successfully delivered through such ternary systems, no information can be found about protein loading and the formulation stability when such microemulsions are prepared with pharmaceuticallyapproved oils and surfactants. The aim of this work was to optimise a ternary system consisting of water/ ethyl oleate/Span bovine serum albutum $(\mathrm{BSA}) \mathrm{a} \overline{\bar{\nu}}$ lodel of biomolecule.
\end{abstract}

\begin{abstract}
Methods: The optimization was carried out using a Central Composite Design and all the prepared formulations were characterised through dynamic light scattering, rheology, optical and polarized microscopy. Subsequently, the maximum loading capacity was determined and the stability of the final microemulsion with the highest content of protein was followed over six months. To investigate the structural features of the protein, BSA was recovered from the microemulsion and analysed through fluorescence spectroscopy.
\end{abstract}

Results: After incorporation of the protein in the microemulsion, a decrease of its aqueous solubility was observed. However, the formulation remained stable over six months and the native-like state of the recovered protein was demonstrated by fluorescence spectroscopy

Conclusion: This study demonstrated the feasibility of preparing microemulsions with the highest content of protein and their long-term stability.

Keywords: Design of experiments (DoE), formulation stability, protein loading, protein solubility, SDS-PAGE, ternary system.

\section{INTRODUCTION}

Microemulsions are optically isotropic and thermodynamically stable liquid systems [1], composed of water, oil and amphiphilic molecules, which find wide applications in several research fields (e.g. pharmaceutical, cosmetic and chemical industries) $[2,3]$.

\footnotetext{
*Address correspondence to these authors at the School of Pharmacy, University of Camerino, via Gentile III da Varano, 62032 Camerino (MC), Italy; Tel: 0737/402289; Fax: 0737/402727; E-mail: giulia.bonacucina@unicam.it; and School of Biosciences and Veterinary Medicine, University of Camerino, via Gentile III da Varano, 62032 Camerino, MC, Italy; Tel: 0737/402722; Fax: 0737/402727; E-mail: ??m????????????
}

$1389-2010 / 17 \$ 58.00+.00$
In the pharmaceutical field, microemulsions have been proposed as drug delivery systems for different routes of administration $[4,5]$ due to their favourable properties, such as spontaneous formation, thermodynamic stability, drug solubility enhancement, low viscosity and the possibility to be sterilized [6-9]. Particularly, microemulsions which present oil as the dispersant and water as the inner $\mathrm{p} \equiv$ (sometimes referred as water in oil, i.e. w/o microemulsion or reverse micelles), have attracted interest by the scientific community since they could represent a suitable vehicle for the delivery of biological therapeutics [10]. In fact, formulations of microemulsion systems for the oral delivery of therapeutically-active peptides have already reached the market 
(cyclosporine; Sandimmune Neoral ${ }^{\circledR}$ ) or are under clinical trial evaluation (insulin, Macrulin ${ }^{\mathrm{TM}}$ ) [11]. Their efficacy to improve the bioavailability of orally-administered macromolecular drugs is related to the ability of protecting protein or peptides from acidic or enzymatic degradation or enhancing their intestinal absorption $[12,13]$.

Many biological products have been reported to be encapsulated in microemulsions [14-17]. Cheng et al. [18], demonstrated that a fibrinolytic enzyme, when incorporated in a w/o microemulsion, possesses a higher intestinal permeability and efficacy in vivo, with the respect to the protein solution. Moreover, Liu et al. found that the HIV transactivator protein loaded in a w/o microemulsion, was protected against acid degradation [19]. The ability of w/o microemulsions to improve storage stability of proteins and catalytic activity of enzymes was also reported [20-22].

However, to act as drug vehicles, the protein loading capacity and the folding state of the protein loaded inside the microemulsions are critical issues.

To date, most of the data on protein loading and formulation stability are available only for microemulsions prepared with organic solvents (e.g. iso-octane) as external phase and high toxic surfactants (e.g. di-octyl sodium sulfosuccinate, AOT) [23-26]. On the contrary, there is a lack of information on microemulsions prepared with pharmaceutical grade excipients and potentially suitable for the in vivo administration of proteins or peptides.

In the present study, a microemulsion, prepared with a pharmaceutically-approved oil (as external phase) and surfactants, has been optimized using a response surface methodology (RSM). Protein loading capacity and formulation stability at the highest content of the protein were studied using bovine serum albumin (BSA) as a model of a macromolecule. Due to the concerns related to the direct investigation of the state of the protein inside the microemulsion, BSA was recovered from the ternary system and analysed by SDS-PAGE and fluorescence spectroscopy.

\section{MATERIALS AND METHOD}

\subsection{Materials}

Ethyl oleate, Tween ${ }^{\circledR} 80$ (Polysorbate 80 ) and Span $^{\circledR} 80$ (Sorbitan monooleate) were supplied by ACEF (Fiorenzuola D'Arda, Italy). Sodium dodecyl sulphate (SDS) (BioReagent $\geq 98.5 \%$ ) and bovine serum albumin (purity $>96 \%$ ) were purchased by Sigma Aldrich (UK). Sodium chloride $(\mathrm{NaCl})$, disodium hydrogen phosphate $\left(\mathrm{Na}_{2} \mathrm{HPO}_{4}\right)$ and potassium dihydrogen phosphate $\left(\mathrm{KH}_{2} \mathrm{PO}_{4}\right)$ were purchased from Carlo Erba (Italy). Deionised water was obtained using a laboratory deionizer (Osmo lab UPW2, Gamma 3, Italy). Isotonic phosphate buffer at $\mathrm{pH} 7.4$ was prepared by dissolving $\mathrm{Na}_{2} \mathrm{HPO}_{4}(22.2 \mathrm{mM}) \mathrm{KH}_{2} \mathrm{PO}_{4}(5.6 \mathrm{mM})$ and $\mathrm{NaCl} 123.3 \mathrm{mM}$ in deionised water.

\subsection{Formulation of Microemulsions}

\subsubsection{Experimental Design}

Response Surface Methodology (RSM) is a reliable statistical approach through which it is possible to study how several factors affect the properties of a pharmaceutical formulation, by generating a mathematical model to predict how the variation of such factors (independent-variables) influence one or more responses (dependent variables).

A "central composite design (CCD) was used to investigate the influence of three factors (e.g. amount of water, amount of surfactant mixture Span ${ }^{\circledR} 80$-Tween ${ }^{\circledR} 80$ and total hydrophilic-lipophilic balance (HLB value) on droplets size, viscosity and stability of ternary systems made up of water/ ethyl oleate/Span ${ }^{\circledR} 80$-Tween ${ }^{\circledR} 80$.

The experiments necessary to study three factors systems through a CCD were the following:

- 8 (23) factorial experiments, defined by the coded variables -1 or 1 .

- $6(2 * 3)$ axial experiments, defined by the coded variables -1.682 or +1.682 .

- 3 repetition of the central point, defined by the coded variable 0 .

All the compositions prepared according to the experimental design are listed in Table 1.

The results for each response were processed by a multiple linear regression on the base of a full quadratic model:

$y=\operatorname{Cos} t+A x_{1}+B x_{2}+C x_{3}+D x_{1} x_{2}+E x_{1} x_{3}+F x_{2} x_{3}+G x_{1}^{2}+H x_{2}^{2}+I x_{3}^{2}$

The significance of the regression and of the individual coefficients was determined by ANOVA analysis and t-test, respectively. Subsequently, this mathematical model was simplified by deletion of not significant terms.

Results were presented using contour plots for each response and then optimized using the graphical method of the overlay plot.

More details concerning the CCD experimental plan and analysis can be found in the literature [27]. The experimental design and its statistical analysis were performed with the software MINITAB ${ }^{\circledR}$ Release 14.1 (Minitab Inc. 1972-2003).

\subsubsection{Sample Preparation}

Tween ${ }^{\circledR} 80$, $\operatorname{Span}^{\circledR} 80$ and ethyl oleate were mixed together until a homogeneous system was obtained. Then, the relative amount of deionised water was added dropwise and the mixture was stirred for $6 \mathrm{~h}$. Each system was stored in tight closed glass vial at $25^{\circ} \mathrm{C}$ for 24 hours before further use.

\subsubsection{Rheological Analysis}

Viscometry tests were used to measure the viscosity of the samples at $25^{\circ} \mathrm{C}$. All tests were performed by increasing the shear rate $(\gamma)$ from 1 to $150 \mathrm{~s}^{-1}$ and the corresponding shear stress $(\sigma)$ was measured, using a rotational rheometer (Stress-Tech, Rheologica, USA) equipped with a 4/40 coneplate geometry.

The shear rate vs shear stress curves was fitted by using the power law equation (equation 2) to calculate the power law viscosity $(K)$ and the power law index (n). 
Table 1. List of the samples prepared according to the central composite design and relative coded and uncoded variables (surfactant mixture \%, water \% and HLB index) values.

\begin{tabular}{|c|c|c|c|c|c|c|}
\hline Samples & \multicolumn{3}{|c|}{ Coded Variables } & \multicolumn{3}{|c|}{ Uncoded Variables } \\
\hline 1 & -1 & -1 & -1 & 20 & 8 & 9 \\
\hline 2 & -1 & +1 & -1 & 20 & 12 & 9 \\
\hline 3 & +1 & -1 & -1 & 30 & 8 & 9 \\
\hline 6 & -1 & +1 & +1 & 20 & 12 & 13 \\
\hline 7 & +1 & -1 & +1 & 30 & 8 & 13 \\
\hline 8 & +1 & +1 & +1 & 30 & 12 & 13 \\
\hline 9 & 0 & -1.682 & 0 & 25 & 6.64 & 11 \\
\hline 12 & +1.682 & 0 & 0 & 33.41 & 10 & 11 \\
\hline 13 & 0 & 0 & -1.682 & 25 & 10 & 7.64 \\
\hline 14 & 0 & 0 & +1.682 & 25 & 10 & 14.64 \\
\hline 15 & 0 & 0 & 0 & 25 & 10 & 11 \\
\hline 16 & 0 & 0 & 0 & 25 & 10 & 11 \\
\hline 17 & 0 & 0 & 0 & 25 & 10 & 11 \\
\hline
\end{tabular}

$\sigma=K \gamma^{n}$

Eq. (2)

All the analyses were performed in triplicate.

\subsubsection{Microscopy and Particle Size Analysis}

All samples were observed with an optical polarised microscope (MT92000, Meiji Techno, JP) to identify whether the systems were nanodisperse and/or isotropic. When the samples were not isotropic, image analysis was used to measure the size of the droplets and/or surfactants aggregates in the micrometric range. Images of samples were collected using a 10X objective lens (MA832 U. Plan Objective 10X, Meiji Techno, JP) and a 3 megapixel camera (Invenio 3S, DeltaPix, DK). Size analyses were performed by using Image Pro Plus Software (Media Cybernetics Inc., USA) measuring the size of at least 100 particles e/o droplets.

The size of isotropic and nanodisperse systems, instead, was characterized by dynamic light scattering measurements (Zetasizer NanoS, Malvern, UK). $1 \mathrm{~mL}$ of the sample was loaded inside a disposable cuvette and analysed at $25^{\circ} \mathrm{C}$ after $180 \mathrm{~s}$ for thermal equilibration. The size of the droplets was calculated according to the distribution model (Malvern Software), correcting the viscosity $\left(10 \mathrm{mPa}^{*} \mathrm{~s}\right)$ and the refractive index (1.46) of the dispersant phase (ethyl oleate/Span ${ }^{\circledR} 80$ Tween $\left.{ }^{\circledR} 80\right)$. Each sample was analysed in duplicate.

\subsubsection{Stability Test}

All the samples prepared according to the experimental design were stored for six months at $25^{\circ} \mathrm{C}$ in tight closed glass vials. Stability was determined assigning to each sample a value corresponding to the time (months) required to turn from a transparent into a turbid or separate system.

\subsection{Hemolytic Assay}

Hemolytic assay was performed to assess the hemolytic activity of the optimized microemulsions selected by the experimental design analysis. The test was performed for a general evaluation of the toxicological properties of the designed formulations. Erythrocytes were collected from mice blood by centrifugation ( $6500 \mathrm{rpm}$ for $\left.10 \mathrm{~min} ; 4^{\circ} \mathrm{C}\right)$, washed three times in an isotonic phosphate buffer solution. A stock suspension was prepared by suspending erythrocytes in the same buffer (cell density of $8 \times 109$ cells $/ \mathrm{ml}$ ). Different volumes of microemulsions, from $5 \mu \mathrm{L}$ to $500 \mu \mathrm{L}$, were tested against $25 \mu \mathrm{L}$ of erythrocytes suspension. The final volume was adjusted to $1 \mathrm{ml}$ in isotonic buffer. The negative control was prepared by $950 \mu \mathrm{L}$ of isotonic buffer, while the positive control was obtained with the same procedure of the negative one but finally frozen at $-20^{\circ} \mathrm{C}$ [29]. All the samples, including positive and negative controls, were gently shaken for 10 minutes at room temperature and centrifuged at $3000 \mathrm{rpm}$ for 5 min. Supernatant was collected and the absorbance was measured at $540 \mathrm{~nm}$ with a UV-Vis spectrometer (UV-1800, Shimadzu corporation). The extent of hemolysis, expressed as percentage $(\mathrm{H} \%)$, was determined by using following equation: 
Table 2. Size (r. $\mathrm{nm})$, viscosity $\left(\mathrm{Pa}^{*} \mathrm{~s}\right)$ and stability (months) of the microemulsions prepared for the validation of the Central Composite Design (samples 18 and 19).

\begin{tabular}{|c|c|c|c|}
\hline Samples & Size (r.nm) & Power Law Viscosity (Pa*s) & Stability (Months) \\
\hline \hline 18 & $40.85 \pm 1.77$ & $0.87 \pm 0.01$ & $>3$ \\
\hline 19 & $52.86 \pm 4.08$ & $2.08 \pm 0.13$ & 1.5 \\
\hline
\end{tabular}

$H(\%)=\frac{A b s_{S}-A b s_{N C}}{A b s_{P C}-A b s_{N C}} \cdot 100$

where:

$A b s_{N C}$ is the absorbance measured in the negative control ( $0 \%$ of hemolysis);

$A b s_{P C}$ is the absorbance measured in the positive control (100\% of hemolysis);

$A b s_{S}$ is the absorbance measured in the samples containing the microemulsion.

The aqueous solution of the two surfactants $\left(\operatorname{Span}^{\circledR} 80\right.$ and Tween ${ }^{\circledR} 80$ ) at the same ratio used in the optimized microemulsion was tested for comparison. Furthermore, sodium dodecyl sulphate (SDS) was used as an example of a well-characterised hemolytic surfactant. All samples were tested in triplicate.

\subsection{Microemulsion Loading Capacity}

The maximum protein loading capacity, using BSA as model protein, was determined on the optimized formulation. BSA was dissolved inside the aqueous phase used for the microemulsion preparation according with the procedure reported in the section 2.2.2. The final BSA concentration ranged between $1 \mathrm{mg} / \mathrm{ml}$ and $24 \mathrm{mg} / \mathrm{ml}$ nolated with respect to the total volume $\bar{\equiv}$ e microemu $\bar{\equiv}$.

\subsection{Characterization and Stability of BSA Loaded Mi- croemulsion}

The microemulsion loaded with the highest amount of BSA was characterized in terms of viscosity and size of the dispersed phase following the methodology previously described (sections 2.2.3 and 2.2.4). All these parameters were monitored over a six months period at $4^{\circ}$ and $25^{\circ} \mathrm{C}$ for stability evaluation.

\subsection{Quantification of the BSA Recovery from the Micro- emulsion}

In order to recover the protein, $1 \mathrm{ml}$ of the microemulsion loaded with the highest amount of BSA the extraction solution (water/acetonitrile 75:25) and gently mixed. The formed emulsion was centrifuged at $13000 \mathrm{rpm}$ for $30 \mathrm{~min}$ at $4^{\circ} \mathrm{C}$. The protein was recovered as pellets and resuspended in isotonic phosphate buffer $(22.2 \mathrm{mM}$ $\mathrm{Na}_{2} \mathrm{HPO}_{4}, 5.6 \mathrm{mM} \mathrm{KH} \mathrm{PO}_{4}$ and $123.3 \mathrm{mM} \mathrm{NaCl}$ ). The recovered protein was quantified through an image analysis of the electrophoretic bands obtained after a polyacrylamide electrophoresis performed under denaturing conditions (SDS-PAGE) and by fluorescence measurements.
SDS-PAGE was performed using $12 \%$ of polyacrylamide/bisacrylamide for the running gel and 3.5\% for stacking gel. $20 \mu \mathrm{L}$ of the samples were boiled $5 \mathrm{~min}$ in the presence of $10 \mu \mathrm{L}$ of sample loading buffer $(1300 \mu \mathrm{L}$ glycerol, $1200 \mu \mathrm{L}$ of $10 \%$ SDS, $600 \mu 1$ ß-mercaptoethanol, $200 \mu \mathrm{L}$ blue bromophenol saturated so $\bar{\equiv}$ ), subsequently loaded into the well of the stacking gel and run by applying a voltage of $200 \mathrm{~V}$. After the running, protein bands were stained using Coomassie Brilliant blue R250 (5 grams dissolved in acetic acid/methanol/water 10:50:40) and the excess of the dye was removed using a destaining solution (acetic ac$\mathrm{id} /$ methanol/water 10:50:40). After destaining, the gel was scanned at 600 dpi resolution, and the gel image was analyzed using PDquest software (Version 7.1.1; Bio-Rad Laboratories). Standard BSA solutions in the range of concentration between $0.05 \mathrm{mg} / \mathrm{mL}$ and $1 \mathrm{mg} / \mathrm{ml} \Longrightarrow$ also run in the same gel to build up a calibration curv ree different samples of the resuspended BSA were run in three independent polyacrylamide gels together with standard solutions.

Fluorescence spectra of the recovered protein (diluted 1 to 5 in buffer or in $6 \mathrm{M}$ and $12 \mathrm{M}$ urea) and standard solution of BSA in buffer phosphate at the same concentrations used in SDS-PAGE were collected at $25^{\circ} \mathrm{C}$ using a Hitachi 4500 spectrofluorimeter. Samples were excited at $280 \mathrm{~nm}$ and the emission intensity was recorded in the range of 300-450 nm.

The recovery of the protein was expressed as percentage with the respect of the nominal loading of the microemulsion.

\section{RESULTS AND DISCUSSION}

\subsection{Formulation of Microemulsions}

The phase behaviour of ternary systems is generally studied by building a ternary phase diagram, which reports the results of a large number of experiments [28, 29]. However, a quicker screening of the factors influencing microemulsion formation can be performed by applying different type of design of experiments (DoE), such as factorial, fractional factorial, Hadamard or even central composite design.

In this work a response surface methodology, the central composite design (CCD), was employed since the number of the experimental factors to be analysed was limited and consequently the number of experiments to be carried out can be kept low.

A CCD allows a mathematical description of the relationship between factors and response, assuring a better understanding of the process, as well as the possibility of the optimization of the process itself [27]. 


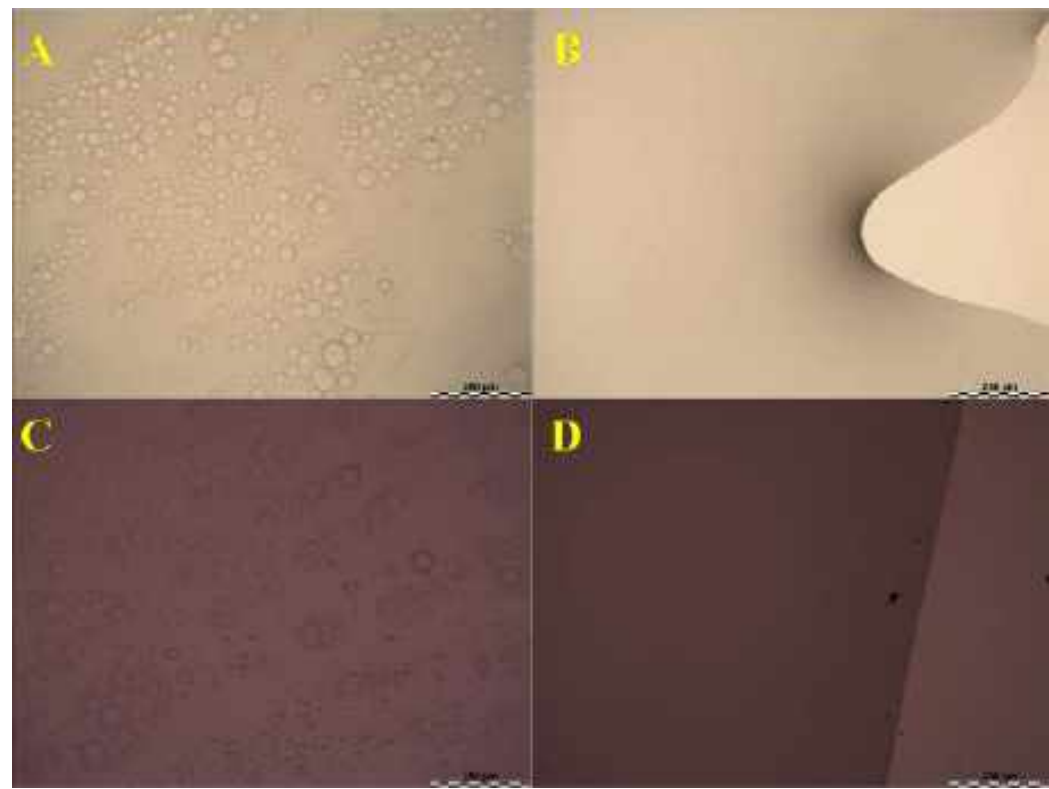

Fig. (1). Microscopy analysis. Optical and polarised light microscope images (10X) of an emulsified system (sample 11) prepared according to the experimental design (A and $\mathbf{C}$ ). Optical and polarised light microscope images (10X) of a homogeneous and isotropic system (sample 7) prepared according to the experimental design (B and $\mathbf{D})$.

The CCD was initially used to understand how the amount of water, of surfactant mixture and the surfactant ratio (HLB value) affected the systems properties such as the size of dispersed phase, the viscosity and the stability.

The presence of micrometric oil droplets in all the samples was evaluated by optical and polarised microscopy. For instance, water droplets in the micrometric range were observed in several samples, e.g. sample 11 (Fig. 1A), indicating the formation of a coarse emulsified system at a macroscopic level. Conversely, other samples, e.g. number 7 (Fig. 1B), appeared homogeneous under observation and consequently were analysed using polarised light and DLS. Under polarised light, these samples did not show any birefringence, appearing as isotropic systems (Fig. 1C and 1D) and showed a monomodal size distribution in the nanometric range when analysed using DLS.

The effect of the three factors on the size of the dispersed phase was analysed with the CCD and the results were described by the following model:

Radius $=10.716+2.946 x_{1}-2.000 x_{2}-3.425 x_{3}-1.825 x_{1} x_{2}-0.733 x_{1} x_{3}-3.558 x_{2} x_{3}$

The multilinear regression resulted to be significant $\left(\mathrm{P}_{\text {value }}=0.016\right)$ when tested with ANOVA. The significant coefficients were only the amount of water $\left(x_{1}\right)$, the HLB value $\left(\mathrm{x}_{3}\right)$ and the interaction between the amount of surfactant and the HLB $\left(\mathrm{x}_{2} \mathrm{x}_{3}\right)$ (SF1). The effect of $\mathrm{x}_{1}$ and $\mathrm{x}_{2}$ on the size, when the surfactant amount is kept constant at $30 \%$, is reported in Fig. (2).

The second analysed response is the viscosity of the systems. All the formulations prepared showed different appearance, from transparent (sample 9) or white (sample 1) liquid, to white (sample 10) or transparent (sample 8) semi- solid. When analysed with the viscometry test, the samples generated stress-strain traces with different trends, representative of both Newtonian and non-Newtonian systems. For example, sample 1 had a power law index of around 1, typical of a Newtonian behaviour, while sample 7 showed a value of 0.68 , characteristic of a pseudoplastic system.

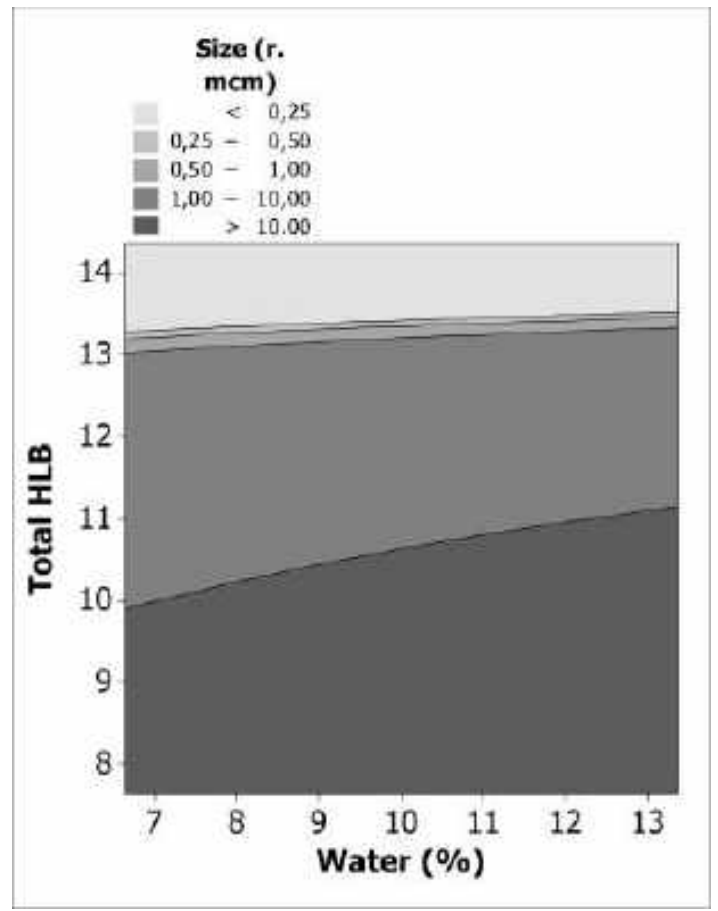

Fig. (2). Analysis of size response. Contour plot representing the effect of water (\%) and total HLB on the size response of the Central Composite Design. The parameter (surfactants \%) is set at $30 \%$. 
Examples of stress-strain traces of samples having different rheological behaviour are reported in Fig. (3) (the figure refers to sample 1, 7 and 9).

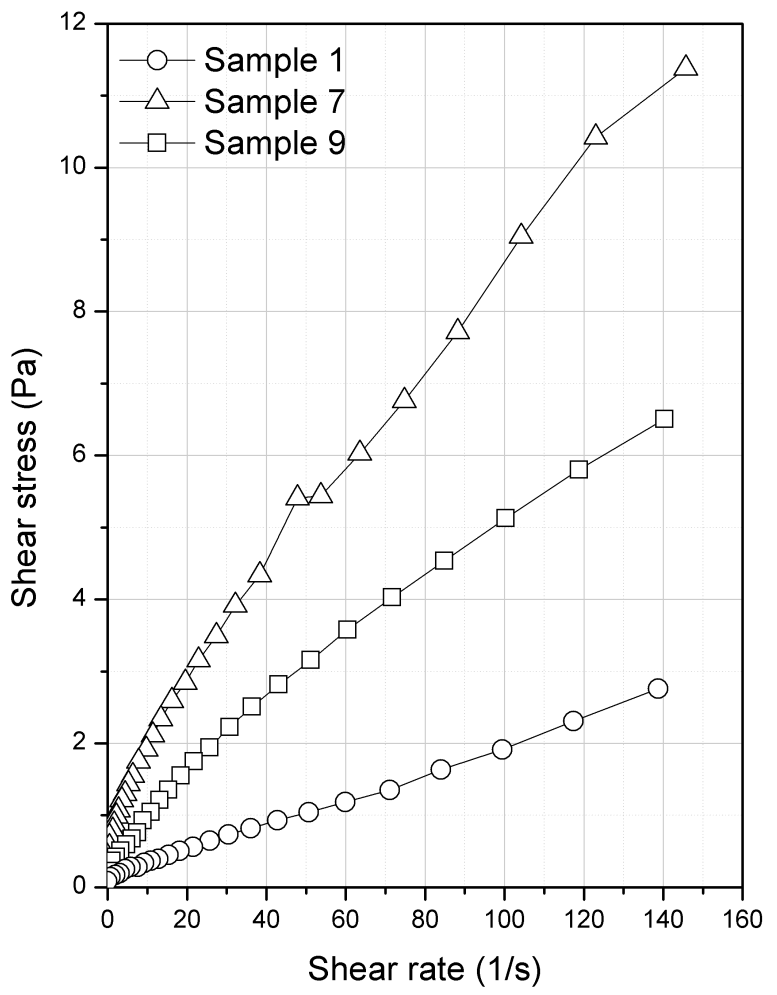

Fig. (3). Rheological analysis. Flow curves from viscometry test performed on sample 1, 7 and 9 prepared according to the experimental design. The figure shows the different rheological behaviour from Newtonian (sample 1) to pseudoplastic (samples 7 and 9).

The model describing the effect of the amount of water $\left(\mathrm{x}_{1}\right)$, amount of surfactant mixture $\left(\mathrm{x}_{2}\right)$ surfactants $\operatorname{HLB}\left(\mathrm{x}_{3}\right)$ on the power law viscosity (PLV) is reported below:

$P L V=0.824+0.531 x_{1}+0.245 x_{2}+0.797 x_{3}+0.264 x_{1} x_{2}+0.534 x_{1} x_{3}+0.606 x_{2} x_{3}$

The multilinear regression resulted to be significant $\left(\mathrm{P}_{\text {value }}=0.014\right)$ when tested with the ANOVA, while all the coefficients were significant with the exception of $\mathrm{x}_{2}$ and the interactions $\mathrm{x}_{1} \mathrm{x}_{2}$ and $\mathrm{x}_{1} \mathrm{x}_{3}(\mathrm{SF} 2)$. As previously observed for the size, also in this case, the HLB value and water content were the most important factors. The increase of both parameters determines a raise of the consistency of the systems. The results of the CCD analysis are reported in Fig. (4) using the contour plot.

Finally, the stability of the systems was analysed. The formulations prepared according to the experimental design were stable for different periods after the end of the stirring, ranging from few minutes (samples 6 and 11) up to several months (samples 7 and 9), with intermediate values of few hours or days.

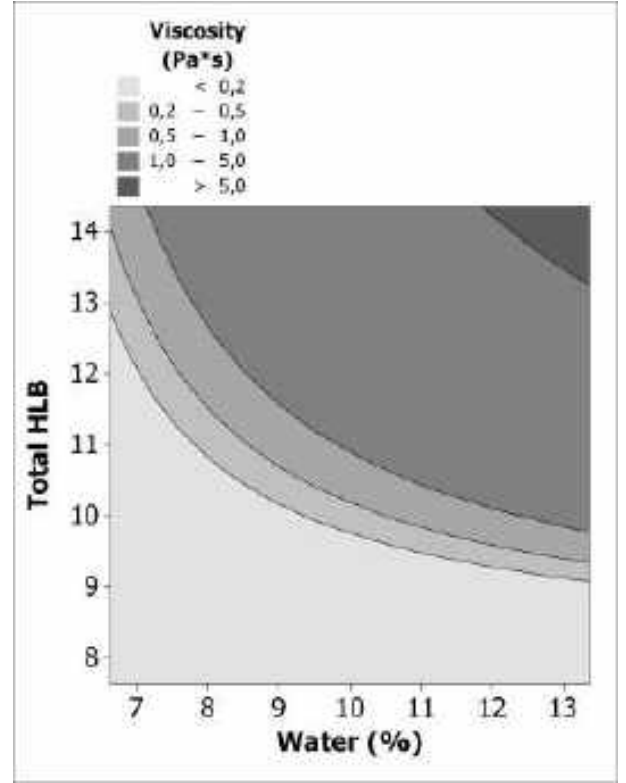

Fig. (4). Analysis of viscosity response. Contour plot representing the effect of water (\%) and total HLB on the viscosity response of the Central Composite Design. The third parameter (surfactants \%) is set at $30 \%$.

The model describing how the stability time (min) is influenced by the different factors is reported below:

Stability $=-4872-50947 x_{1}+19172 x_{2}+19091 x_{3}+44339 x_{1}^{2}$

As for the others responses analysed, the multilinear regression resulted to be significant $\left(\mathrm{P}_{\text {value }}=0.011\right)$ when tested with the ANOVA, while only the coefficients relative to the amount of water, both as linear and quadratic terms, were significant (SF3). The results of the CCD analysis, when the surfactant amount is kept constant at $30 \%$, are reported in Fig. (5) using the contour plot.

The three determined models allowed understanding how the different factors affect each single response, which could be therefore optimized (find specific experimental conditions able to generate a certain response) individually. However, in order to obtain the best system, it is necessary to optimize all the three responses at the same time. To achieve this goal, the graphical optimization procedure was selected. Such procedure involves the superposition of each contour plot on top of each other in a single graph (overlay plot). The optimized systems are those having values of the responses all within the acceptability range. The acceptability limits were selected to define the experimental conditions at which the size of the internal phase and the viscosity of the ternary systems were minimized, while the stability of the same system was maximized. By selecting a size (radius) for the internal phase lower than $300 \mathrm{~nm}$, a power law viscosity lower than 0.5 $\mathrm{Pa}^{*} \mathrm{sec}$ and a stability higher than three months (129600 $\mathrm{min}$ ), a feasibility area can be found only on the overlay plot water (\%) vs. HLB with a total amount of surfactant at $30 \%$ (Fig. 6). From this specific overlay plot it can be observed that a suitable system can be formed only in a very narrow 


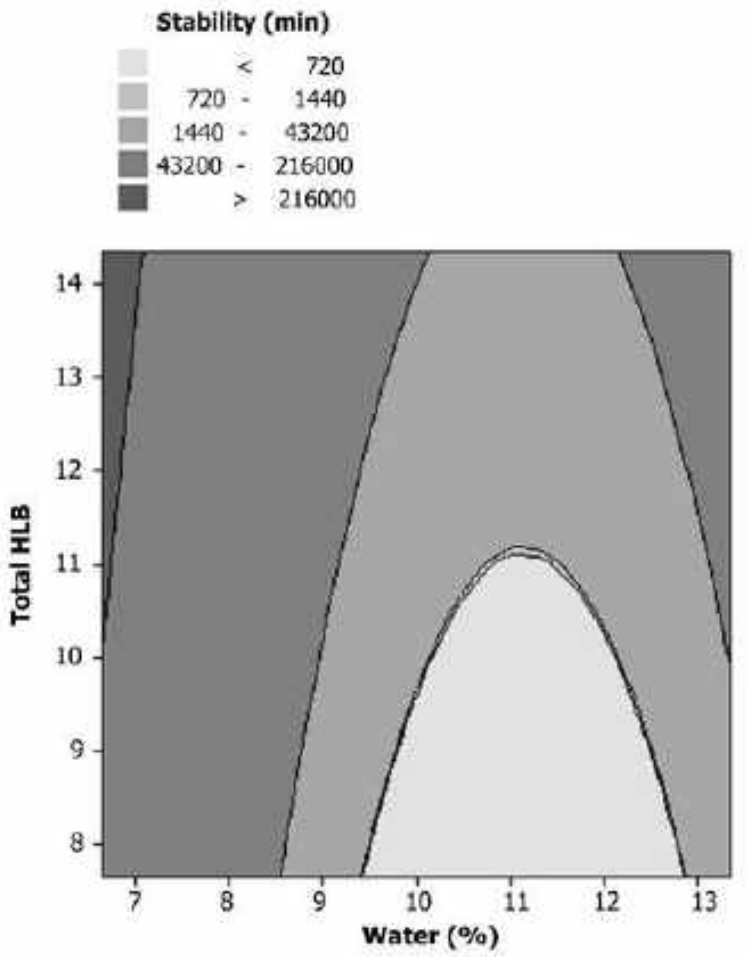

Fig. (5). Analysis of stability response. Contour plot representing the effect of water (\%) and total HLB on the stability response of the Central Composite Design. The third parameter (surfactants $\%$ ) is set at $30 \%$.

area (red area in the Fig. 6). Specifically, the HLB value has to be between 13.2 and 13.4 and the amount of water between $6.5 \%$ and $6.9 \%$ (lower amount are also possible but they are not taken into account since they are outside the experimental domain of the CCD) for a total amount of surfactant at $30 \%$.

The effectiveness of the experimental design was validated by analysing two additional samples (samples 18 and 19). The first one was prepared using the experimental conditions inside the feasibility area whereas the second one using the conditions outside of it hy thin the limit of the size for a colloidal dispersion. Th mposition of these two formulations (indicated in the Fig. (6) as black circle and triangle respectively) was as follows:

Sample 18: amount of water $6.7 \%$, HLB value 13.3 and amount of surfactant mixture $30 \%$;

Sample 19: amount of water 10\%, HLB value 13.4 and amount of surfactant mixture $30 \%$.

According with the overlay plot these two samples should possess similar size of the internal phase but different viscosity and stability.

These two samples were prepared with the same procedure used for all the formulations of the experimental design and analysed as before. The experimental values for each
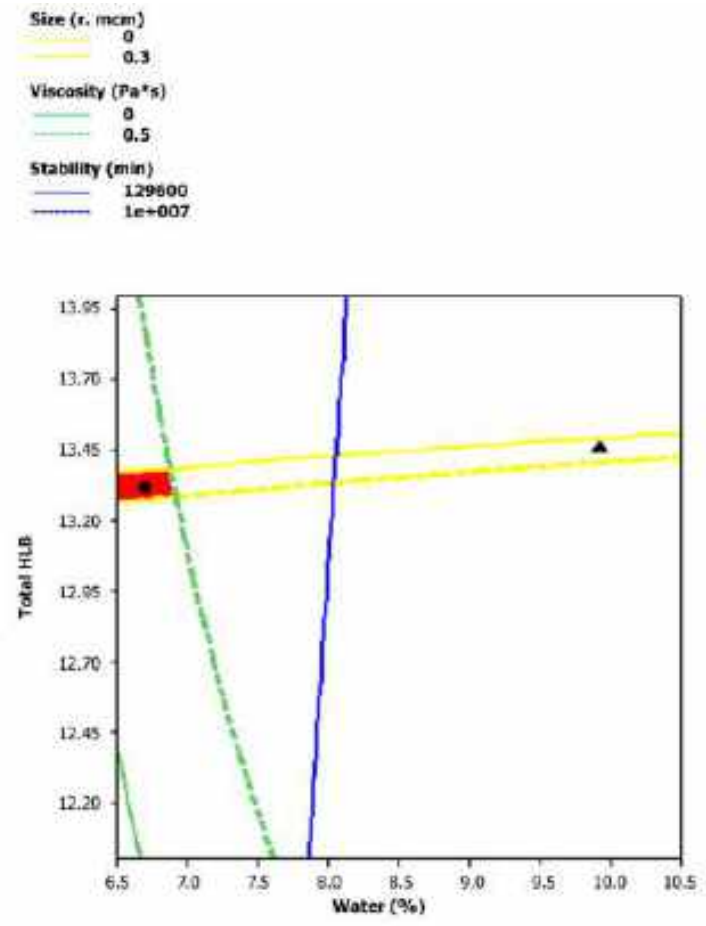

Fig. (6). Optimization of the ternary system. Overlay plot combining the effect of water (\%) and total HLB on the three responses (size, viscosity and stability) of the Central Composite Design. The third parameter (surfactants \%) is set at $30 \%$. The red area in the graph represents the region inside the experimental domain where the size, viscosity and stability parameters of the microemulsion are optimized. The black circle and triangle represent the composition of the two additional samples used for the validation of the central composite design.

response were quite close to those predicted by the overlay plot. Specifically, an increase in water content from $6.7 \%$ to $10 \%$ maintained the size of the internal phase below $0.5 \mu \mathrm{m}$, but determined a sharp increase in viscosity (from 0.87 to $2.08 \mathrm{~Pa}^{*} \mathrm{~s}$ ). These results confirmed the validity of the prediction model and consequently validated the effectiveness of the experimental design in the optimisation of the parameters affecting the formulation of a ternary system.

\subsection{Haemolytic Assay}

A general estimation of the toxicity of the two microemulsions prepared for the validation of the experimental design (sample 18 and 19) was assessed by haemolytic assay. In addition, water solution of surfactant mixtures (Span ${ }^{\circledR}$ 80 -Tween ${ }^{\circledR} 80$ ) at the same ratio used for the preparation of microemulsions number 18 and 19 were also tested. Fig. (7) shows the haemolysis (\%) with respect to the tested volume of microemulsion or surfactant mixtures $(\mu 1)$ To this extent, it is known from the literature [29] that Twe 80 is a nonhaemolytic surfactant, differently to Span 80 that exhibits moderate haemolytic properties [30]. The culated haemolysis (\%) was found to be much lower than $50 \%$ for both the microemulsions (around 5-10\%) and surfactant mixtures (around $10-15 \%$ ). Consequently, the $\mathrm{HC}_{50}$ values could not be calculated. Moreover, no difference between surfactant mixtures and microemulsions can be observed up to $150 \mu \mathrm{L}$ 
and just a slight increase in haemolysis for both the surfactant mixtures occurred after the addition of 300-500 $\mu \mathrm{L}$ of samples. The accuracy of the method was evaluated by testing SDS, a well-known haemolytic surfactant. In such case, increasing volumes of SDS solution $(2 \mathrm{mg} / \mathrm{mL})$ were tested up to $100 \%$ of haemolysis and the $\mathrm{HC}_{50}$ value was calculated. Such value $(45 \mu \mathrm{g} / \mathrm{mL})$ was comparable to that reported in the literature [30].

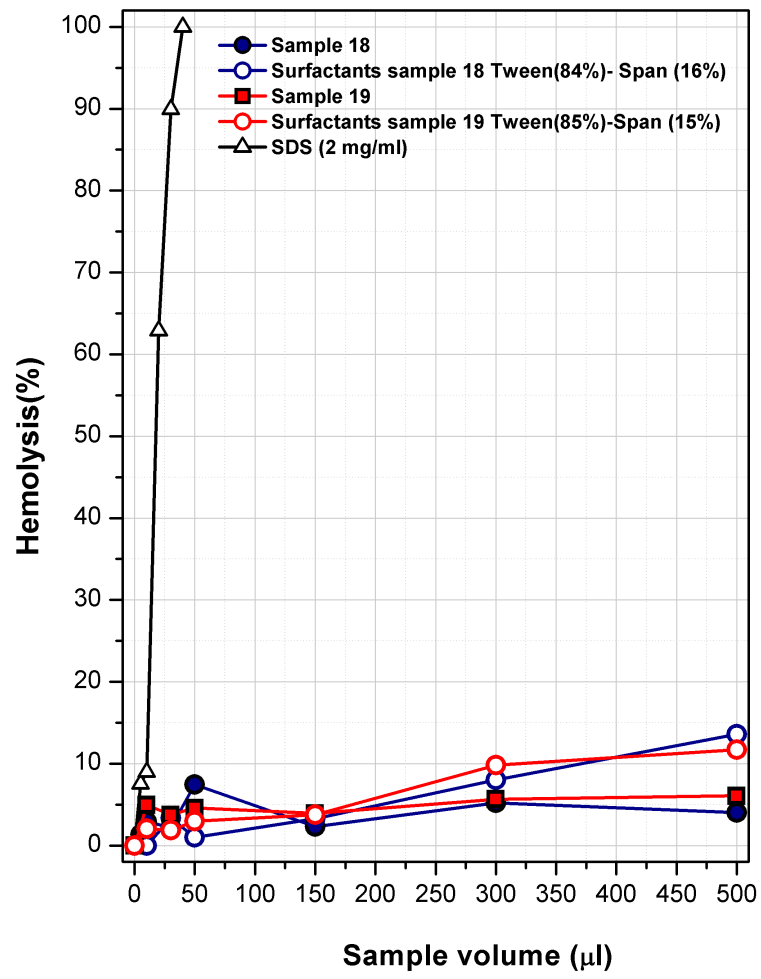

Fig. (7). Haemolytic assay. Haemolysis (\%) versus sample volume $(\mu \mathrm{L})$ of microemulsions prepared for the validation of the Central Composite Design (samples 18 and 19) in comparison to surfactant mixtures (Tween $80^{\mathbb{R}}$ and Span $80^{\mathbb{R}}$ ) and SDS as reference.

\subsection{BSA Loading Capacity in Microemulsion}

The evaluation of the loading capacity, especially in the case of proteins, is a neglected aspect in the formulation process of microemulsions. Nevertheless, it is important to know how much protein can be loaded inside the internal aqueous phase when ternary systems are employed as vehicles for the delivery of therapeutically-active protein through different routes of administration.

To this extent, an initial screening using BSA at a concentration between $24 \mathrm{mg} / \mathrm{mL}$ and $1 \mathrm{mg} / \mathrm{mL}$ was performed and the samples homogeneity was analysed through visual observation. All the systems prepared with a BSA concentration from 24 to $4 \mathrm{mg} / \mathrm{mL}$ appeared turbid just after the preparation, while microemulsions loaded with $1 \mathrm{mg} / \mathrm{mL}$ and 2 $\mathrm{mg} / \mathrm{mL}$ BSA appeared clear. All samples were, then, stored at $25^{\circ} \mathrm{C}$. Significantly, after $48 \mathrm{~h}$, a phase separation occurred in the microemulsions displaying a BSA concentration from $24 \mathrm{mg} / \mathrm{mL}$ to $6 \mathrm{mg} / \mathrm{mL}$. On the other hand, samples at $4 \mathrm{mg} / \mathrm{ml}, 2 \mathrm{mg} / \mathrm{ml}$ and $1 \mathrm{mg} / \mathrm{ml}$ of BSA concentration did not show an $\bar{\equiv}$ serva $\overline{\overline{\bar{y}}}$ changes $\overline{\bar{\equiv}}$ compared to the same samples just after the preparation. $4 \mathrm{mg} / \mathrm{mL}$ BSA microemulsion remained turbid, instead, $2 \mathrm{mg} / \mathrm{L}$ and $1 \mathrm{mg} / \mathrm{mL}$ BSA-microemulsions resulted clear (Fig. 8A and B).

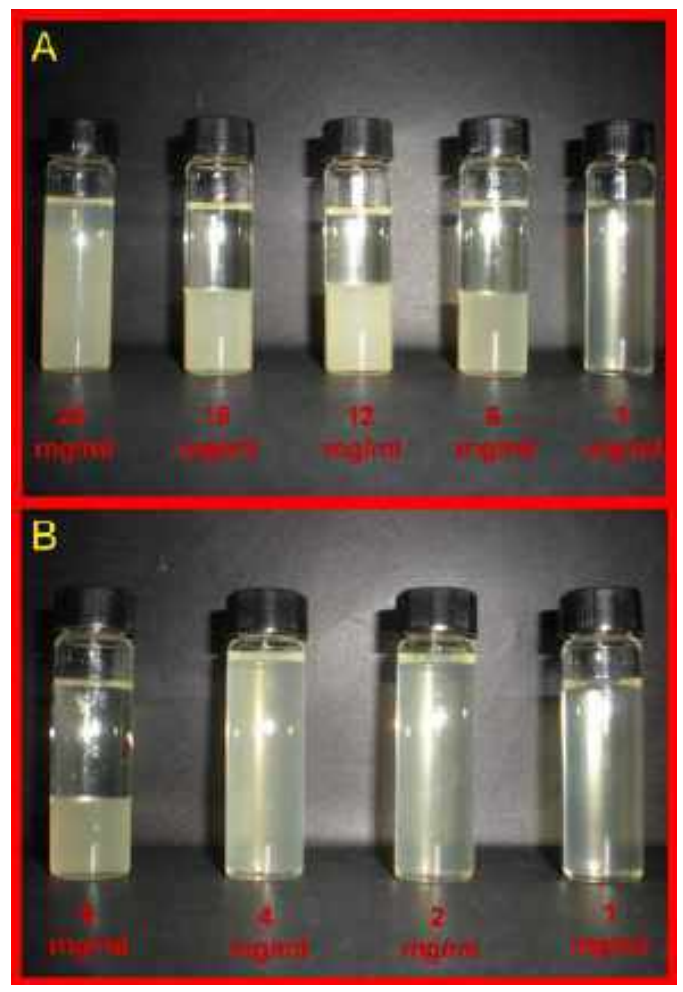

Fig. (8). BSA loading capacity in the microemulsion. Visual observation after a $48 \mathrm{~h}$ of storage time at $25^{\circ} \mathrm{C}$ of the microemulsion, selected according to the Central Composite Design (sample 18) and prepared at different BSA concentrations from $24 \mathrm{mg} / \mathrm{mL}$ to 1 $\mathrm{mg} / \mathrm{mL}(\mathbf{A})$ and from $6 \mathrm{mg} / \mathrm{mL}$ to $1 \mathrm{mg} / \mathrm{mL}(\mathbf{B})$.

The samples were also analysed through optical microscopy to examine whether the presence of BSA could destabilize the microemulsion. From the pictures in Fig. (9), it can be observed that there is no presence of large $(>1 \mu \mathrm{m})$ droplets at any BSA concentration after the preparation, denoting that the presence of the protein did not cause the coalescence of the internal phase of the microemulsion. However, samples that appeared turbid at the visual inspection, showed the presence of insoluble particles. The amount of these particles markedly decreased from $24 \mathrm{mg} / \mathrm{mL}$ BSA-microemulsion (Fig. 9A) to $6 \mathrm{mg} / \mathrm{mL}$ BSA-microemulsion (Fig. 9B) suggesting that, at those concentrations, the protein precipitated. Microemulsions at $1 \mathrm{mg} / \mathrm{mL}$ and $2 \mathrm{mg} / \mathrm{mL}$ appeared clear also under microscopic observation (Fig. 9C). From these results, it can be deduced that BSA does not disrupt microemulsion structure, but the turbidity of samples is only due to protein precipitation.

In order to confirm this hypothesis, the upper and the lower phase of $48 \mathrm{~h}$ stored samples, in which a phase separation occurred, were $\bar{\equiv}$ ected and observed by optical microscopy. The upper phase appeared clear in all samples (Fig. 9D); the lower phase, instead, showed insoluble particles (Fig. 9E) appearing quite similar to those observed in the same sample immediately after the preparation. 


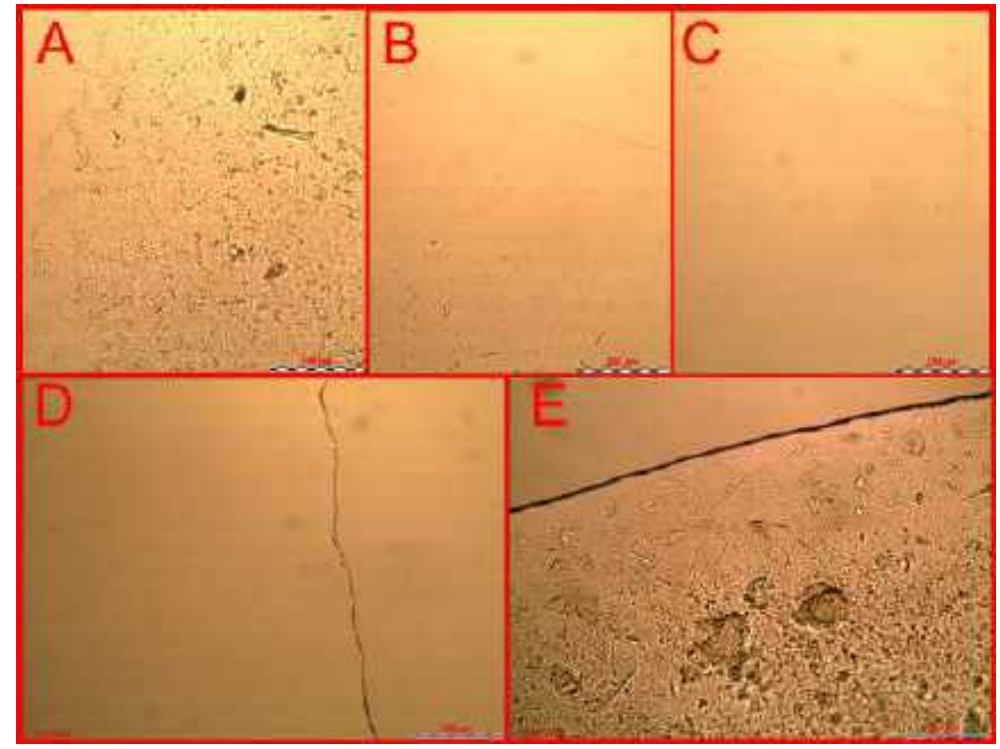

Fig. (9). BSA loading capacity in the microemulsion. Optical microscope images (10X) of BSA-loaded microemulsions after the preparation: $24 \mathrm{mg} / \mathrm{mL}(\mathbf{A}), 6 \mathrm{mg} / \mathrm{mL}$ (B) and $2 \mathrm{mg} / \mathrm{mL}$ (C). Images of the upper phase (D) and lower phase (E) from $24 \mathrm{mg} / \mathrm{ml}$ BSA-loaded microemulsion after storage $48 \mathrm{~h}$ at $25^{\circ} \mathrm{C}$.

Table 3. Viscosity $\left(\mathrm{Pa}^{*} \mathrm{~s}\right)$, power law index value (n) and size (r. $\mathrm{nm}$ ) for the optimized microemulsion (sample 18) and the same microemulsion loaded with $2 \mathrm{mg} / \mathrm{mL}$ of $\mathrm{BSA}$, calculated after preparation and after storage at $25^{\circ} \mathrm{C}$ and $4^{\circ} \mathrm{C}$ for six months.

\begin{tabular}{|c|c|c|c|}
\hline & Viscosity (Pa*s) & Index (n) & Size (r.nm) \\
\hline \hline Microemulsion & $0.870 \pm 0.120$ & $0.568 \pm 0.013$ & $40.85 \pm 1.77$ \\
\hline BSA-loaded microemulsion $^{*}$ & $0.970 \pm 0.155$ & $0.571 \pm 0.032$ & $42.82 \pm 3.50$ \\
\hline Microemulsion stored 6 months at $\mathbf{2 5}^{\circ} \mathbf{C}$ & $0.902 \pm 0.160$ & $0.554 \pm 0.021$ & $40.66 \pm 2.86$ \\
\hline BSA-loaded microemulsion stored 6 months at $\mathbf{2 5}^{\circ} \mathbf{C}$ & $0.992 \pm 0.127$ & $0.595 \pm 0.024$ & $45.25 \pm 4.26$ \\
\hline Microemulsion stored 6 months at $\mathbf{4}^{\circ} \mathbf{C}$ & $1.292 \pm 0.151$ & $0.465 \pm 0.049$ & $44.30 \pm 4.05$ \\
\hline BSA-loaded microemulsion stored 6 months at $\mathbf{4}^{\circ} \mathbf{C}$ & $1.283 \pm 0.172$ & $0.464 \pm 0.017$ & $49.63 \pm 6.84$ \\
\hline
\end{tabular}

It is interesting to note that the solubility of BSA in pure water is very different from the solubility of BSA in the water entrapped in microemulsion. In fact, all stock solutions of the protein in water, from which BSA-loaded microemulsions were prepared, appeared clear or slightly yellowish depending on protein concentration, but no precipitation event occurred within $48 \mathrm{~h}$ at room temperature.

On the contrary, when these solutions were incorporated in the oily phase a marked reduction of solubility was observed. A decrease in solubility, leading to protein precipitation at a certain time after the incorporation inside the microemulsions, has also been reported for AOT-isooctane-water ternary systems [31-33].

Solubility of BSA in water (no particles were observed through optical microscope after $48 \mathrm{~h}$ of storage time) was found higher than $358 \mathrm{mg} / \mathrm{mL}$, which is the concentration of BSA solution used to prepare the microemulsion loaded with $24 \mathrm{mg} / \mathrm{mL}$ of the protein. Interestingly, if we consider the solubility of BSA respect to water, when incorporated inside the microemulsion, it decreased to around $29 \mathrm{mg} / \mathrm{mL}$. Thus, the confinement of water inside a microemulsion and/or the presence of high amount of surfactant caused the desolvation of the protein (BSA $>2 \mathrm{mg} / \mathrm{mL}$ of the total volume of the microemulsion) and consequently its cipitation at a concentration of protein higher than $6 \mathrm{mg} / \mathrm{mL}$. This is probably due to the fact that water molecules in a ternary systems are mostly bounded on surfactants molecules and are less available to be engaged in solvation shells around the solutes, especially in the case of macromolecules as proteins [34,35]. Comparable solubility values for proteins (lysozyme and chymotrypsin) around $1-2 \mathrm{mg} / \mathrm{ml}$ were found in microemulsions prepared with organic solven $\bar{\equiv} 3$.

\subsection{Storage Stability of BSA-loaded Microemulsion}

The effect of the storage time and temperature $\left(25^{\circ} \mathrm{C}\right.$ and $4^{\circ} \mathrm{C}$ ) on the stability of the sample 18 loaded with the highest amount of BSA $(2 \mathrm{mg} / \mathrm{mL})$ was investigated by visual and microscopic inspection, DLS measurements and viscometry 
test. The ebtained results were compared to those obtained from the same systems without the protein in order to assess if the presence of the protein at the maximum solubility level can affect microemulsion stability.

All the samples remained transparent and isotropic during all the stability period at the two tested temperatures when visually observed or analysed under microscopy. Table 3 reports the value for power law viscosity, power law index and size for both free or BSA-loaded microemulsion after preparation and after storage at $4{ }^{\circ} \mathrm{C}$ and $25^{\circ} \mathrm{C}$ for six months. The presence of BSA at the maximum solubilisation level (2 $\mathrm{mg} / \mathrm{ml}$ ) did not increase the size of internal droplets both after pr $\bar{\equiv}$ ation and after the storage at $25^{\circ} \mathrm{C}$ and $4^{\circ} \mathrm{C}$. The same behaviour has also been observed for BSA-free microemulsion. Moreover, the loading of BSA did not change the viscosity of the system nor its pseudoplastic behaviour (power law index $\approx 0.5$ ). A slight increase of the viscosity (from 0.9 to $1.2 \mathrm{~Pa}^{*} \mathrm{~s}$ ) was only observed for the samples stored at $4^{\circ} \mathrm{C}$ both for loaded and unloaded samples. Taken together, the analysis of macroscopic properties (appearance, viscosity) and the measurement of the droplet size of the microemulsion demonstrated the thermodynamic stability of these protein-loaded systems over time for at least six months.

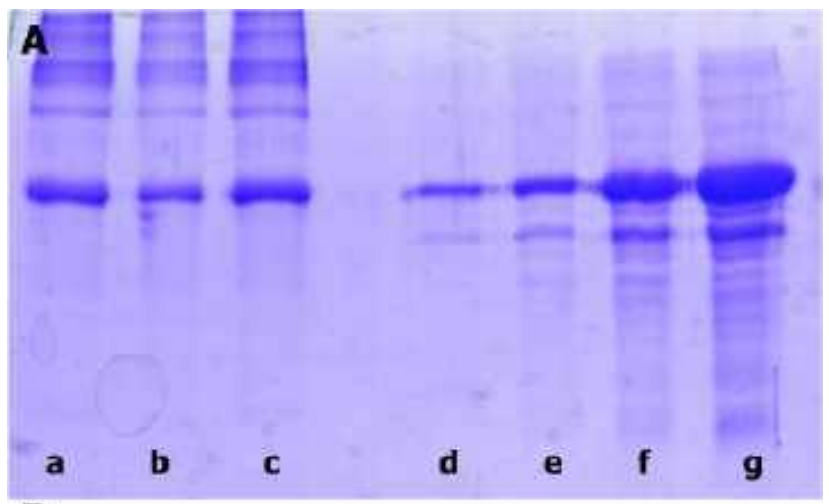

B

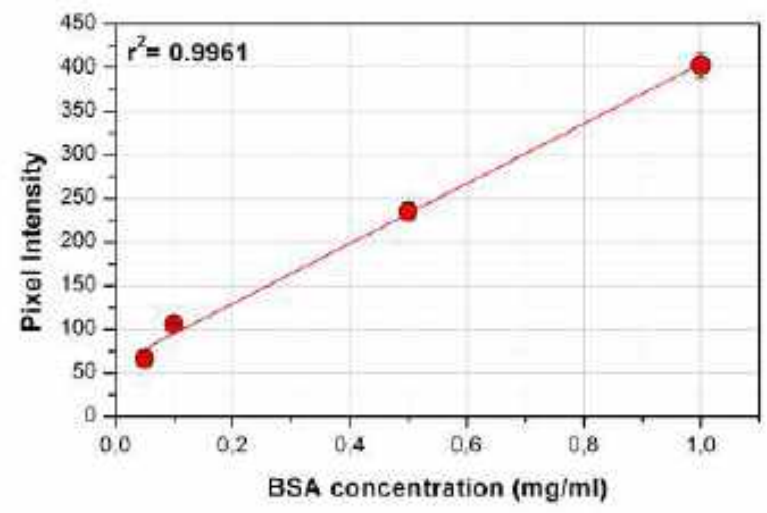

Fig. (10). Quantification of BSA recovery from microemulsion by SDS-PAGE. (A) SDS-PAGE gel: a-c lanes are the recovered protein in isotonic phosphate buffer, $d-f$ lanes are BSA standard solutions in isotonic phosphate buffer at different concentrations (from $0.05 \mathrm{mg} / \mathrm{mL}$ to $1 \mathrm{mg} / \mathrm{mL}$ ). (B) Calibration curve build up by plotting the pixel intensity of the electrophoretic bands relative to BSA standard solution at different concentrations.

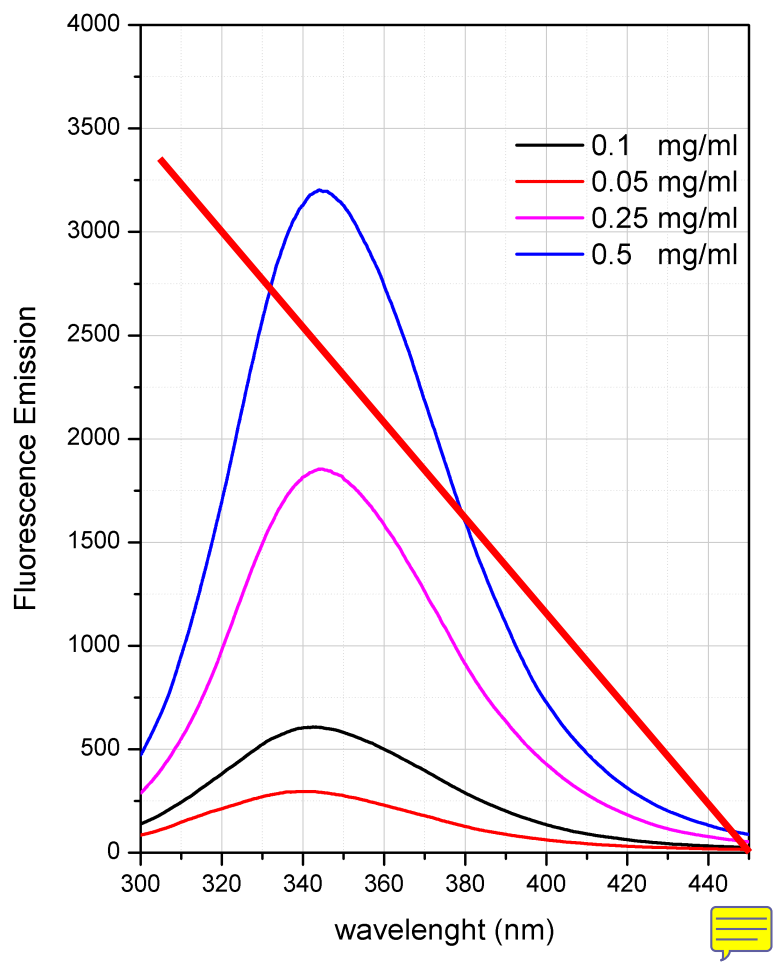

Fig. (11). Fluorescence spectra of the recovered BSA from microemulsion in isotonic phosphate buffer, $6 \mathrm{M}$ and $12 \mathrm{M}$ urea water solutions.

\subsection{Quantification of the Recovered BSA}

The protein recovered by the microemulsion loaded with the maximum amount of BSA was quantified through the spot image analysis of the gel from SDS-PAGE (densitometric analysis) as described before. This technique was widely employed in molecular biology or proteomics [36], but its use is yet underestimated for protein quantitative analysis in pharmaceutics.

Figure 10A showed the scanned polyacrylamide gel from electrophoresis. The lanes a-c refer to the samples from microemulsions in triplicates, while the lanes d-g refer to standard solution of BSA at the concentration range 0.1-1 $\mathrm{mg} / \mathrm{ml}$ It can be noticed from the lanes referring to BSA standa $\equiv$ lutions (d-g), the presence of the main high intensity band (indicated by and arrow in the figure) related to the to the $66 \mathrm{kDa}$ fraction of the protein and a secondary lesscoloured band at a slighter low molecular weight (BSA purity $\geq 96 \%$ from the manufacturer). Nevertheless, when the protein is overloaded inside the gel (f-g; concentration $\geq 0.5$ $\mathrm{mg} / \mathrm{mL}$ ) several fainted bands of different molecular weights appeared. According to the literature, the bands at molecular weight lower than $66 \mathrm{kDa}$ can be identified as BSA peptide fragments, while those at higher molecular weight as dimeric or trimeric forms of the protein $[37,38]$.

As shown in the figure 10B, a linear dependence of the pixel intensity of the main band obtained from the running of BSA standard solutions at different concentrations was observed and used to build up the calibration curve. The $\mathrm{R}^{2}$ of the fitting linear regression curve obtained from the BSA standard solution in the three independent gels was higher 
than 0.976 . Using these calibration curves, the percentage of the recovered BSA from microemulsion $(69.37 \pm 6.65 \%)$ was calculated by the estimation of the pixel intensity of the main band.

Interestingly, the recovered BSA showed bands with shorter electrophoretic path with higher intensity than BSA standard used for the calibration curve. These bands can be ascribed to the formation of protein aggregates due to a polymerization process [39]. In order to understand if these differences in the electrophoretic pattern are due to the condition of the protein inside the microemulsion or to the recovery process, SDS-PAGE was also performed on the protein solution treated with the same extraction mixture (water/acetonitrile 75:25) and then centrifuged (30 min, 13000 rpm). In this case, the bands relative to the aggregates of the protein were of less intensity with respect to those observed by running the protein extracted from the microemulsion (SF4). This result confirms that the extraction process does not influence the aggregation state of BSA.

The quantification of the protein was also performed by fluorescence measurements. A calibration curve using standard solution of BSA in isotonic buffer was built $\left(\mathrm{R}^{2}>0.997\right)$ (SF5). The calculated recovery was $51.66 \pm 3.1 \%$. As it can be observed from the fluorescence spectra (Figure 11) the maximum emission wavelength of the recovered BSA (diluted 1 to 5 in isotonic buffer) is around $340 \mathrm{~nm}$, which is comparable to that of a native protein. When urea as denaturing agent is added, the recovered protein showed the characteristic spectral changes of a pure BSA solution as reported in the literature [40]. In particular, in presence of $6 \mathrm{M}$ of urea a blue shift from $340 \mathrm{~nm}$ to $334 \mathrm{~nm}$ occurred due to a change in the hydrophobicity in the microenvironment around tryptophans. Instead, by increasing the concentration of urea up to $12 \mathrm{M}$ a red shift occurred to $346 \mathrm{~nm}$ due to the unfolding of the protein and the exposure of tryptophan residues to the solvent's hydrophilic environment. Overall, fluorescence spectra confirmed the maintenance of a native-like state of the recovered protein.

\section{CONCLUSION}

In this work, a stable and non-toxic microemulsion system made up of water/ethyl oleate/ $\operatorname{Span}^{\circledR} 80$-Tween ${ }^{\circledR} 80$ was optimized through a central composite design and loaded with the maximum amount of the protein. Our results suggest that the confinement of water, as in a microemulsion system, strongly affects the solubility of the protein, when compared with its aqueous solution. Particularly, a marked decrease in water solubility of the protein was observed after incorporation in the microemulsion. This aspect should be considered anytime when such systems are formulated for the delivery of macromolecules, as biotherapeutics. Moreover, the formulation showed a long-term stability, also when the protein was incorporated close to the saturation point in the aqueous compartment, suggesting the feasibility of preparing microemulsions at the highest content of proteins. Finally, a method for the recovery of the protein from a microemulsion formulated with approved oil and surfactants has been proposed and the native-like behaviour of the recovered BSA as a model of macromolecules, has been demonstrated through SDS-PAGE and fluorescence spectroscopy.

\section{ETHICS APPROVAL AND CONSENT TO PARTICI- PATE}

Not applicable.

\section{HUMAN AND ANIMAL RIGHTS}

No Animals/Humans were used for studies that are base of this research.

\section{CONSENT FOR PUBLICATION}

Not applicable.

\section{CONFLICT OF INTEREST}

The authors confirm that this article content has no conflict of interest.

\section{ACKNOWLEDGEMENTS}

Declared none.

\section{SUPPLEMENTARY MATERIAL}

Supplementary material is available on the publisher's web site along with the published article.

\section{REFERENCES}

[1] Danielsson, I.; Lindman, B. The definition of microemulsion 1981; 3: 391-92.

[2] Tenjarla S. Microemulsions: An Overview and Pharmaceutical Applications 1999; 16: 62.

[3] Altria K. Application of microemulsion electrokinetic chromatography to the analysis of a wide range of pharmaceuticals and excipients 1999; 844: 371-86.

[4] Lawrence MJ, Rees GD. Microemulsion-based media as novel drug delivery systems 2000; 45: 89-121.

[5] Narang AS, Delmarre D, Gao D. Stable drug encapsulation in micelles and microemulsions 2007; 345: 9-25.

[6] Bonacucina G, Cespi M, Misici-Falzi M, Palmieri GF. Colloidal soft matter as drug delivery system 2009; 98: 1-42.

[7] Paolino D, Ventura CA, Nisticò S, Puglisi G, Fresta M. Lecithin microemulsions for the topical administration of ketoprofen: percutaneous adsorption through human skin and in vivo human skin tolerability 2002; 244: 21-31.

[8] Yuan Y, Li S, Mo F, Zhong D. Investigation of microemulsion system for transdermal delivery of meloxicam 2006; 321: 117-23.

[9] Špiclin P, Gašperlin M, Kmetec V. Stability of ascorbyl palmitate in topical microemulsions 2001; 222: 271-79.

[10] Sarciaux JM, Acar L, Sado PA. Using microemulsion formulations for oral drug delivery of therapeutic peptides 1995; 120: 127-36.

[11] Park K, Kwon IC, Park K. Oral protein delivery: Current status and future prospect 2011; 71: 280-87.

[12] Constantinides PP, Scalart J-P, Lancaster C, Marcello J, Marks G, Ellens $\mathrm{H}$, et al. Formulation and Intestinal Absorption Enhancement Evaluation of Water-in-Oil Microemulsions Incorporating Medium-Chain Glycerides 1994; 11: 1385-90.

[13] Lyons KC, Charman WN, Miller R, Porter CJH. Factors limiting the oral bioavailability of $\mathrm{N}$-acetylglucosaminyl-N-acetylmuramyl dipeptide (GMDP) and enhancement of absorption in rats by delivery in a water-in-oil microemulsion 2000; 199: 17-28.

[14] Gao Z-G, Choi H-G, Shin H-J, Park K-M, Lim S-J, Hwang K-J, et al. Physicochemical characterization and evaluation of a microemulsion system for oral delivery of cyclosporin A 1998; 161: 7586.

[15] Constantinides PP, Lancaster CM, Marcello J, Chiossone DC, Orner D, Hidalgo I, et al. Enhanced intestinal absorption of an 
RGD peptide from water-in-oil microemulsions of different composition and particle size 1995; 34: 109-16.

[16] Fan Y, Li X, Zhou Y, Fan C, Wang X, Huang Y, et al. Improved intestinal delivery of salmon calcitonin by water-in-oil microemulsions 2011; 416: 323-30.

[17] Sharma G, Wilson K, van der Walle CF, Sattar N, Petrie JR, Ravi Kumar MNV. Microemulsions for oral delivery of insulin: Design, development and evaluation in streptozotocin induced diabetic rats 2010; 76: 159-69.

[18] Cheng M-B, Wang J-C, Li Y-H, Liu X-Y, Zhang X, Chen D-W, et al. Characterization of water-in-oil microemulsion for oral delivery of earthworm fibrinolytic enzyme 2008; 129: 41-48.

[19] Liu D, Kobayashi T, Russo S, Li F, Plevy SE, Gambling TM, et al. In Vitro and In Vivo Evaluation of a Water-in-Oil Microemulsion System for Enhanced Peptide Intestinal Delivery 2013; 15: 288-98.

[20] Abel S, Waks M, Urbach W, Marchi M. Structure, Stability, and Hydration of a Polypeptide in AOT Reverse Micelles 2006; 128: 382-83.

[21] Noritomi H, Takasugi T, Kato S. Refolding of denatured lysozyme by water-in-oil microemulsions of sucrose fatty acid esters. 2008; 30: 689-93.

[22] Orlich B, Schomäcker R. Advances in Biochemical Engineering/Biotechnology. Springer Berlin Heidelberg 2002.

[23] Rairkar ME, Hayes DG, Harris JM. Solubilization of enzymes in water-in-oil microemulsions and their rapid and efficient release through use of a pH-degradable surfactant 2007; 29: 767-71.

[24] Matzke SF, Creagh AL, Haynes CA, Prausnitz JM, Blanch HW. Mechanisms of protein solubilization in reverse micelles. 1992; 40: 91-102.

[25] Chemelli A, Maurer M, Geier R, Glatter O. Optimized Loading and Sustained Release of Hydrophilic Proteins from Internally Nanostructured Particles 2012; 28: 16788-97.

[26] Shipovskov S, Oliveira CLP, Hoffmann SV, Schauser L, Sutherland DS, Besenbacher F, et al. Water-in-oil micro-emulsion enhances the secondary structure of a protein by confinement. 2012; 13: 3179-84

[27] Lewis GA, Mathieu D, Phan-Tan-Luu R. Pharmaceutical Experimental Design. CRC Press 1998.
[28] Bonacucina G, Cespi M, Mencarelli G, Casettari L, Palmieri GF. The use of acoustic spectroscopy in the characterisation of ternary phase diagrams 2013; 441: 603-10.

[29] Bonacucina G, Cespi M, Mencarelli G, Palmieri GF. Characterization of ternary phase diagrams by means of thermal and rheological analyses. 2013; 39: 1547-54

[30] Aparicio RM, José García-Celma M, Pilar Vinardell M, Mitjans M. In vitro studies of the hemolytic activity of microemulsions in human erythrocytes 2005; 39: 1063-67.

[31] Lye GJ, Asenjo JA, Pyle DL. Extraction of lysozyme and ribonuclease-a using reverse micelles: Limits to protein solubilization 1995; 47: 509-19.

[32] Hayes DG. Mechanism of protein extraction from the solid state by water-in-oil microemulsions 1997; 53: 583-93.

[33] Iyer M, Hayes DG, Harris JM. Synthesis of pH-degradable nonionic surfactants and their applications in microemulsions 2001; 17: $6816-21$

[34] McClements DJ. Nanoemulsions versus microemulsions: terminology, differences, and similarities 2012; 8: 1719-29.

[35] Zampieri GG, Jaeckle H, Luisi PL. Determination of the structural parameters of reverse micelles after uptake of proteins 1986; 90: 1849-53.

[36] Magdeldin S, Enany S, Yoshida Y, Xu B, Zhang, Zureena Z, et al. Basics and recent advances of two dimensional- polyacrylamide gel electrophoresis 2014; 11: 16

[37] Kshirsagar B, Wilson B, Wiggins RC. Polymeric complexes and fragments of albumin in normal human plasma 1984; 143: 265-73.

[38] Zhu G, Mallery SR, Schwendeman SP. Stabilization of proteins encapsulated in injectable poly (lactide- co-glycolide) 2000; 18: 52 57.

[39] Saha S, Deep S. Switch in the aggregation pathway of bovine serum albumin mediated by electrostatic interactions. 2014; 118: 9155-66.

[40] Kumaran R, Ramamurthy P. Denaturation Mechanism of BSA by Urea Derivatives: Evidence for Hydrogen-Bonding Mode from Fluorescence Tools 2011; 21: 1499-1508. 